\title{
ACCEPTANCE OF INCLUSION AMONG REGULAR EDUCATION TEACHERS IN THE PHILIPPINES
}

\author{
Maria Corazon C. Colendrino* \\ De La Salle University-Manila, Philippine
}

\begin{abstract}
For more than a century, Filipino children with disabilities (CWDs) were placed in special classes according to their presenting educational needs. But in support of the global call for equal and equitable education, and that of upholding the CWDs' human right to be educated alongside peers in the regular education (RE) classroom, the Philippine education system has declared itself inclusive. The issue of its acceptance by RE teachers was raised. Mixed method research was conducted during a seminar/workshop that defined inclusion and discussed inclusive teaching strategies. Convenient sampling had 199 pre-seminar and post-seminar survey respondents in conference attendees. Focus group discussion (FGD) divided the participants by regions of origin to discuss in depth the possible impact of the nationwide implementation of inclusion to the teaching and learning process. Pre-seminar survey results showed that $80 \%$ of the respondents initially favored inclusion. Post-seminar survey and FGD results showed that majority of the respondents at 97\% shifted preference to mainstreaming. This was explained by the following: 1) confusion in the meaning of terms: mainstreaming was being practiced but understood to be inclusion; 2) the zeroreject policy in the public school system includes children with behavioral disorders and raised safety concerns; and 3) the RE teachers lack expertise and experience in handling CWDs in the RE classroom. Recommended were clarification on the definition of terms so the RE teachers would know the scope of their work and the extent of their responsibilities; intensive training in Special Education, and more researches on educational placement.
\end{abstract}

Keywords: integration, mainstreaming, inclusion

\section{Introduction}

Special Education has been in existence in the Philippines for more than a century. It opened its first school in the country in 1907, the Insular School for the Deaf and the Blind (Inciong, 2005, Consolacion, N.D.,) catering to the needs of leaners with sensorial disabilities. Highly segregated, it addressed issues presented by blindness and hearing difficulties that could not then be addressed by the regular education (RE) curriculum. The field has evolved through the years and addressed other conditions that required very particular curriculum content, delivery system, evaluation, learning environment, and teaching personnel: physical disabilities (1945), intellectual disability (1953), emotional and behavioral disabilities (1962), and giftedness (1963) (Consolacion, N.D.). Increasing disability awareness in the succeeding years addressed issues on autism, learning disabilities, communication disorders, attention deficit and hyperactivity disorder, and other health impairments and conditions that can get in the way of learning.

Filipino children with disabilities (CWDs) were placed in special classes according to their presenting educational needs. Segregation was a local and global practice, highly justified by the then inability of the RE system to teach learners with special needs in the RE classroom. The RE teachers lacked or had no training in Special Education, and could not effectively teach them while teaching the RE students as well. Segregation was actually done to accord CWDs equal opportunities in learning (Hunt, J. T., 1957).

But while such segregation has its purpose and merits, some people deemed it unfair and fought for the right of special learners to be educated in the regular education classroom. Part of the argument was based on the US 
Supreme Court decision on the landmark case of Brown versus the Board of Education of Topeka in 1954 which ruled that separation is not equal, and ended the legal segregation of colored and white children (Justia, 2018). While the latter was a racial discrimination case, it proved instrumental in the crafting of laws and policies on segregation and integration especially in education.

No less than the United Nations advocate for the right of all children to be integrated in the RE system. The then Millennium Development Goal 2: Achieve Universal Primary Education, aimed to eradicate poverty by 2015, in part, by giving all children equal access to primary education (United Nations, N.D.). The present Sustainable Development Goal 4: Ensure Inclusive and Equitable Quality Education and Promote Lifelong Learning Opportunities for All aims to ensure that equal and equitable educational opportunities are accessible even in higher education, including colleges and universities (United Nations, N.D.).

In support of the call to uphold the CWDs' human right to be educated alongside peers in the regular education classroom, and that of the global call for equal and equitable education, the Philippine education system has declared itself inclusive. As inclusion puts the Filipino CWDs under the direct responsibility of the RE teachers, the issue of its acceptance by the latter was raised: how are they reacting to the nationwide implementation of inclusion?

This study forms part of a bigger research on the acceptance of inclusion as an educational system in the country by the members of the Philippine society where situational analysis further looks into the implications of the paradigm shift.

\section{Related Literature}

The educational placement of learners with very particular needs has always been a sensitive issue. The question on what merits integration into, and segregation from, the regular education system has been debated over and over. An online search on educational placement and rights of persons with disabilities will yield results on studies published in academic journals, local and international laws and policies, and opinionated blogs and articles. Global and local citizens have vastly differing views on where and how special children should be best educated. Evelyn Deno (1970) proposed a cascade of services, ranging from the most integrated to the most segregated, catering to all imaginable educational placement needs with varied support via adaptation in the delivery system. This supports the standpoint of Hunt (1957) on segregation actually according CWDs equal learning opportunities.

Four of the more popular educational placement options in the continuum of services are integration, mainstreaming, inclusion, and special classes (segregation). The first three have been used interchangeably by some; and explicitly differentiated by others. Confusion in definition might be explained by the fact that these are very common terms of everyday usage that have been assigned particular meanings in the education community. The following traces history and defines each.

Integration was one of the major goals achieved by the Civil Rights Movement (Library of Congress, 2018) and is primarily a legal term (AIR, 2017). It is a "carry over from the civil rights/racial desegregation legislation of the 1960s and before;" and goes beyond the physical integration of children from marginalized groups into society, including but not limited to, academics and social integration (AIR, 2017). But integration puts the burden of adaptation on the children and those who could not cope were pulled out from the RE to join special classes (Thomazet, 2008). For more severe disabilities, integration has been reduced to joining RE in non-academic classes, mostly for socialization purposes.

Mainstreaming is a form of integration. It is selective in nature. In the Individuals with Disabilities Education Act (IDEA) of the United States of America, it is often 
referred to as the least restrictive environment (LRE) that a child can be placed in as long as it provides him/her with appropriate education (Wright and Wright, 2018). It assumes that the "student must earn his or her opportunity to be mainstreamed through the ability to keep up with the work assigned by the teacher to the other students in the class" (Rogers, 1993 as cited in AIR, 2018). The primary responsibility of educating the children remained with the Special Education teacher (AIR, 2017).

Inclusion is not mandated by law and is not a legal term. It represented a paradigm shift from the highly criticized integration of the early years to the inclusive education of the Regular Education Initiative (REI), a movement that advocated for the merger of RE and Special Education (Wang, et al. 1986, as cited by Thomazet, 2008). Instead of the child adapting to the learning environment and complying with its requirements, the tables have been turned: the burden has been put on the school institution to educate the child in the most effective way possible in the company of RE students without disabilities. The primary responsibility of educating the children has been passed on to the RE teacher (Thomazet, 2008).

The Regular Education Initiative (REI) was proposed by the then US Assistant Secretary for the Office of Special Education and Rehabilitative Services Madeline Will to form a partnership between RE and Special Education. It invited varying interpretations, and two of the most popular were written by Fuchs and Fuchs (1998) and Wang and Walbert (1998), in criticism and in support of, respectively. Wang and Walbert (1998) wrote the Four Fallacies of Segregationism to clarify what REI is all about. It claimed that contrary to the misinterpretation, the said partnership was not designed to "eliminate or subordinate special education services," but proposes a "shared responsibility" between the two systems. The REI then brings back the CWDs to the RE classroom but brings back Special Education with it, calling for the improvement in delivery system via continuous experimentation. Fuchs \& Fuchs (1998) in reply pointed out the efficacy of the Special Education system in addressing the unique needs of CWDs; and the argument that "careful consideration of students and (educational) settings must precede the widespread implementation of large-scale full time mainstreaming" by citing studies. They reacted strongly to the supposed devaluing of special education where special educators were seen as predators and noneducators.

The existence of opposing views is not only inevitable but understandable. The REI and the possible total shift to inclusive education could shake up the Special Education field and question its ontology and epistemology. Is Special Education giving or hindering equal and equitable educational opportunities to children with diverse needs? Is it helping them by giving them placement options under a continuum of services, planned learning environments, specialized teaching materials, highly trained teachers, and differentiated instruction and evaluation? Or is it curtailing their human right to be educated in the mainstream by even considering pulling them out of the classroom for remedial or special classes? While Special Education began with the worthiest of intensions (the former), it is now being regarded as oppressive (the latter), and something to be avoided at all costs given the call for equality and equity.

Global support for inclusion abounds. The Salamanca Statement and Framework of Action on Special Needs Education, better known worldwide by its shorter title of The Salamanca Statement, was adopted by the World Conference on Special Needs Education held in in Salamanca, Spain in 1994 (CSIE, 2018). It upheld the fundamental principle that "all children should learn together, wherever possible, regardless of any difficulties or differences that they may have" (Inciong, 2005). 
The United Nations, through the United Nations Educational, Scientific and Cultural Organization (UNESCO) sees inclusion as supportive of the bigger program of Education for All. It views it as "a dynamic approach of responding positively to pupil diversity and of seeing individual differences not as problems, but as opportunities for enriching learning." At its core is one's right to equal and equitable educational opportunities, as stated by the Universal Declaration of Human Rights in 1948 (UNESCO, 2005).

Through the years, inclusion became a byword, representing the most desired educational placement by groups advocating for the children's human right to non-selective integration.

\section{Methodology}

This study looked into the acceptance of RE teachers of inclusion as an educational system through quantitative and qualitative lenses. Mixed method research was conducted, employing pre-seminar and post-seminar oral surveys and focus group discussions (FGD).

Convenient sampling had 199 respondents in conference attendees. FGD divided the participants by regions of origin to discuss in depth the possible impact of the nationwide implementation of inclusion to the teaching and learning process.

\section{Results and Discussion}

During the seminar, the different educational placements available to students manifesting learning difficulties were presented and defined to introduce the concept of inclusion. The purpose and target clientele of each were discussed in depth. The workshop that followed on inclusive teaching strategies focused on practical interventions for common learning issues and materials production.

The pre-seminar survey was conducted to determine who among the teachers undergoing training in inclusive teaching strategies were actually in favor of the system. It rested on the premise that before one can be effective in delivery, one has to have an unwavering faith in it. $80 \%$ signified that they were in favor of inclusion. After the seminar/workshop, post-seminar survey and FGD results showed that majority of the respondents at $97 \%$ shifted preference to mainstreaming. This was explained by the following:

\section{There was confusion in the meaning of terms}

Some of the respondents/conference attendees were already practicing mainstreaming where the CWDs were placed in RE based on their ability to adapt. The CWDs were given assistance via pull-out, remedial classes, and shadow teaching. This definition is consistent with the one given in the study of Rogers in 1993 (as cited in AIR, 2017), which assumed that the "student must earn his or her opportunity to be mainstreamed through the ability to keep up with the work assigned by the teacher to the other students in the class."

This type of integration, however, is called inclusion in the public schools. The children were not placed in classes solely on the basis of human rights, but on the CWD's educational needs and ability to cope as well. Thus, the pre-survey resulted in $80 \%$ of the respondents favoring inclusion when they were actually favoring mainstreaming.

With the REI proposing "shared responsibility" instead of the misconception that the RE teacher will be solely responsible for the education of the CWD, $97 \%$ were willing to give inclusion a chance.

2. There is zero-reject policy in the public school system

While majority of the attendees were willing to integrate CWDs in the RE classroom, the inclusion of children manifesting severe behavioral disorders raised safety concerns for both the teachers and the students. Questions 
on proper intervention, qualified personnel to administer such intervention, and the rights of teachers and students to a safe learning environment were asked.

FGD allowed the respondents to share their classroom experiences in handling such cases. Filipino humor made otherwise depressing stories light, as they talked about their feelings of frustration and helplessness in encountering aggression in class. The teachers have very little knowledge on what could really work and some were employing trial and error. Success stories were few and far between and the need for training in behavior management was expressed.

\section{RE teachers lack expertise and experience in Special Education:}

Special Education as an undergraduate program takes about 4 years to complete. The graduates are highly trained in handling CWD issues to maximize potential. For RE teachers, determining potential and contextualizing the curriculum would require intensive training and acculturation. They would need to know the nature and characteristics of the different disabling conditions.

The conference attendees were just starting to learn about inclusive teaching strategies in a 3-day seminar/workshop and deemed themselves inadequate to teach CWDs in RE full time. Willingness and eagerness were expressed but they wanted more preparation in order to be effective in delivery. While the positive impact of inclusion could be huge for CWDs, the possible negative impact of the lack of readiness on the part of teachers could be just as huge for all stakeholders, echoing the concerns raised by Fuchs \& Fuchs (1998).

\section{Conclusion and Recommendations}

The result of the initial study on the acceptance of inclusion by the RE teachers is actually positive. Favoring mainstreaming was indicative of readiness - or the lack of it—at this point. The attendees did not reject the idea of an inclusive system. They were more than willing to include CWDs in their classes but needed more time and training to better prepare themselves for the task. The following recommendations were thus given:

\section{Clarification on the definition of terms}

There is a need to clarify the definition of integration, mainstreaming, and inclusion. While integration and mainstreaming are legal terms, inclusion is not. There are different definitions of inclusion with some versions resembling integration and mainstreaming.

The RE teachers need to know the scope of their work under the inclusive system of education. They need to know their exact duties and responsibilities, given that they would be the ones primarily responsible for the education of the CWDs. They need to know how they can effectively partner with the Special Education teachers to ensure that the CWDs are actually accorded equal and equitable educational opportunities.

\section{Intensive training in Special Education}

Special Education was not part of the pre-service training of the RE teachers until very recently. Chances are high that like the conference attendees, other RE teachers would need intensive training on the nature and characteristics of disabilities for acculturation purposes, and intensive training on the teaching and learning process in Special Education, including but not limited to differentiated instruction, differentiated evaluation, and behavior management.

\section{More researches on educational placement}

Based on the exchanges between Fuchs and Fuchs (1998) and Wang and Walbert (1998), the pros and cons of inclusion can be quite overwhelming. Add to these the global push for inclusion, the international policies 
advocating for equality and equity, and the legal issues on placement, and one can only surmise the kind of challenge that the RE and Special Education teachers could be up against. Recommended are more researches on the acceptance and actual implementation of inclusion in the Philippines.

\section{Acknowledgement}

Acknowledgement is given to the conference attendees who wished to share their points of view on the practice of integration with the public.

\section{References}

AIR (2017), Toward a definition of inclusion. Date of access: 4/1/ 2018. http://www.sedl.org/change/issues/issues43/definition_inclusion.html

CSIE (2018). The UNESCO Salamanca Statement. Date of Access: 4/2/2018. http://www.unesco.org/education/pdf/SALAMA_E.PDF

Consolacion, G. (n.d.) The development of Special Education in the Philippines. Department of Education, Philippines.

De Torres, M. S. (2008). One hundred years of special education in the Philippines, 1907-2007. College of Education, University of the Philippines, Diliman, Quezon City, Philippines

Deno, E. (1970). Special education as developmental capital. Exceptional Children. 37, 229-23

Fuchs, D. \& Fuchs, L. (1998). Response to Wang and Walberg. Exceptional Children. Oct,1988, Vol. 55 Issue 2, p138. Date of access: 4/1/ 2018. http://www.freepatentsonline.com/article/ExceptionalChildren/6722706.html

Hunt, J. T. (1957). Special education: segregation. Education. April,1957, Vol. 77 Issue 8, p475. Date of access: 4/1/ 2018. http://connection.ebscohost.com/c/articles/19112070/special-education-segregation

Inciong, T. (2005). The development of welfare and education for children with mental retardation towards inclusion: the Philippine experience. Conference on the Development of Welfare and Education of Children With Mental Retardation In Asia Towards Inclusive Education, July 9-10, 2005, Seisa University, Hokkaido, Japan. Date of access: 4/1/ 2018. https://aboutphilippines.ph/files/The-Development-of-Welfare-and-EducationFor-Children-with-Mental-Retardation.pdf

Justia (2018). Brown v. Board of Education of Topeka, 347 U.S. 483 (1954). Date of access: 4/1/ 2018. https://supreme.justia.com/cases/federal/us/347/483/case.html

Library of Congress (2018). School segregation and integration. Date of access: 4/1/ 2018. https://www.loc.gov/collections/civil-rights-history-project/articles-and-essays/school-segregation-andintegration/

Thomazet, S. (2008). Integration has limits, not inclusive school! Journal of Educational Sciences, 34 (1), 123 139. DOI: 10.7202 / 018993ar. Date of access: 4/1/ 2018. http://id.erudit.org/iderudit/018993ar

United Nations (n.d.). Goal 2: achieve universal primary education. Date of access: 4/1/ 2018. http://www.un.org/millenniumgoals/education.shtml

United Nations (n.d.). Sustainable Development Goal 4: Ensure inclusive and equitable quality education and promote lifelong learning opportunities for all. Date of access: 4/1/ 2018 . https://sustainabledevelopment.un.org/sdg4 